\title{
Migrations et mutations des systèmes agraires : la culture brésilienne du soja au Paraguay
}

Sylvain Souchaud

\section{OpenEdition}

Édition électronique

URL : https://journals.openedition.org/remi/1649

DOI : $10.4000 /$ remi. 1649

ISSN : $1777-5418$

Éditeur

Université de Poitiers

\section{Édition imprimée}

Date de publication : 1 juillet 2002

Pagination : 105-137

ISBN : 2-911627-30-X

ISSN : 0765-0752

Référence électronique

Sylvain Souchaud, « Migrations et mutations des systèmes agraires : la culture brésilienne du soja au Paraguay ", Revue européenne des migrations internationales [En ligne], vol. 18 - n² | 2002, mis en ligne le 09 juin 2006, consulté le 14 avril 2022. URL : http://journals.openedition.org/remi/1649 ; DOI : https://doi.org/10.4000/remi.1649

Ce document a été généré automatiquement le 14 avril 2022.

(c) Université de Poitiers 


\title{
Migrations et mutations des systèmes agraires : la culture brésilienne du soja au Paraguay
}

\author{
Sylvain Souchaud
}

1 Envisager les interactions migration-environnement revient à considérer que «la migration n'est pas seulement un facteur de régulation des «surplus démographiques", mais qu'elle provoque également des transformations dans les systèmes de production et d'usage des ressources naturelles, et agit en conséquence sur les écosystèmes » (Picouet et Domenach, 1995 : 112-113).

2 Afin d'analyser ces effets nous considérerons la catégorie particulière de migrants que sont les pionniers, en l'occurrence brésiliens. Ces ruraux installés en limite de l'œkoumène sont plus que des défricheurs isolés en lisière forestière s'assurant une subsistance fragile par une maigre production agricole, image qui leur est le plus volontiers donnée. À l'instar des populations rurales en général, les colons-pionniers «ne cherchent plus seulement à se nourrir mais à investir leur force de travail dans une production globale...» (Picouet et Domenach, 2000 : 106). La portée de leurs activités, centrées sur l'implantation d'une agriculture spéculative (soja, café, ...), dépasse ainsi les limites du terroir et s'évalue dans une perspective globale intégrant changements écosystémiques et altérations socio-spatiales.

3 Ces «retoucheurs" sont des aménageurs actifs (Pébayle, 1989), investissant des écosystèmes climaciques qu'ils redéfinissent (Dollfus in I.H.E.A.L, 1981), ils modèlent les paysages en y intégrant l'évolution des socio-systèmes.

4 Les colons brésiliens, qui se contentaient jusqu'à une époque récente d'être des migrants internes ont, pour la première fois de leur histoire, franchi en masse la frontière internationale, donnant ainsi davantage d'envergure à leur action.

5 Depuis une trentaine d'années, le front pionnier lusophone a investi les marges orientales du territoire paraguayen. Cette vague d'immigration d'une ampleur sans précédent marque une révolution dans le domaine agricole, secteur d'activité essentiel à la formation de la société paraguayenne. À la fin du $x^{e}$ siècle, les pionniers et 
descendants de pionniers brésiliens seraient environ 500000 au Paraguay, soit près de $10 \%$ de la population totale du pays. Ils sont appelés, les « Brésiguayens ». L'espace de colonisation brésilienne est encore dominé par une agriculture spéculative sur sols forestiers destinée essentiellement à la production du soja qui alimente le marché agroindustriel international.

Le système, inédit au Paraguay, de production intensive de soja, clé de voûte du schéma socio-spatial de la migration brésiguayenne, sera au centre de notre étude. Il est en général d'usage d'en mentionner l'importance décisive en envisageant son implication sur des processus comme la marginalisation des populations rurales, occupées à des activités dites traditionnelles (polyculture vivrière et/ou commerciale), ou la dégradation des écosystèmes. Sans remettre en cause ces effets essentiels, nous souhaitons cependant décrire ici plus en détail l'activité agricole afin de définir son originalité et certains de ses impacts, peu connus, sur le système agraire paraguayen. En inversant les termes de l'étude, c'est-à-dire en partant non plus des mutations qui atteignent les paysanneries traditionnelles pour arriver à la mise en cause et à la définition partielle du système de la monoculture intensive, mais en tentant une description et une analyse de ce secteur il doit être possible d'en mesurer la portée réelle sur le système agraire du Paraguay.

7 Le centre du dispositif socio-spatial brésiguayen est désigné sous le terme portugais de granja: propriété agricole entièrement motorisée pratiquant la monoculture familiale et intensive du soja. Les parcelles totalement nettoyées (défrichées et essouchées), d'une superficie moyenne avoisinant les 50 ha, sont assemblées en un dispositif quadrangulaire et régulier parcouru de routes et de pistes rectilignes le long desquelles se positionnent, à intervalles réguliers, de petites villes et colonies. L'ordonnancement hiérarchisé de ce paysage caractéristique de l'openfield contraste fortement avec le moutonnement de la forêt tropicale qui le précédait ou encore avec les espaces de polycultures sur brûlis et d'élevage extensif dominant, jusque-là le paysage rural du Paraguay.

Dans un monde rural historiquement caractérisé par ses déséquilibres fonciers et sa faible capacité d'occupation de l'espace, la structure agraire granjeira d'un type nouveau insuffle-t-elle une partie de sa nouveauté ? Outre les atteintes brutales portées aux écosystèmes, les granjeiros entretiennent-ils ces écosystèmes anthropisés et fortement contraints? Enfin, dans quelle mesure le processus migratoire contribue à développer une forme de ruralité jusque-là inconnue, intégrant une relation villescampagnes inédite au Paraguay?

Système agraire et organisation socio-spatiale du Paraguay

9 Par nature, le système agraire paraguayen contribue à la formation de fortes ruptures socio-spatiales mêlant pressions foncières et formation d'espaces de très faibles densité humaine, vacuités potentiellement mobilisables par le monde rural. C'est dans cette situation que les pionniers brésiliens vont trouver une place.

Des déséquilibres du système agraire aux disparités socio-spatiales

10 Le taux d'urbanisation du Paraguay est le plus faible du sous-continent : $55 \%$ en 1998 (Banque mondiale, 2001), le secteur primaire occupe $35 \%$ de la population active en 1995 (Banco Central del Paraguay, 1998) et il participe à hauteur de 28 \% au PIB en 1999 (Banco Central del Paraguay, 2000). Abstraction faite des changements récents intervenus dans le système agraire paraguayen suite à la colonisation brésilienne, certaines marques anciennes définissent l'agriculture paraguayenne dont nous 
retiendrons trois caractères principaux. Elle accuse d'importants déséquilibres dans la répartition des activités, déséquilibres remarquables à diverses échelles d'observation. Sous l'effet d'une structure foncière inégalitaire, on observe une sous-occupation du territoire paraguayen malgré une forte demande en terre de la part des paysanneries locales. Enfin, l'agriculture paraguayenne se caractérise par une production très peu diversifiée.

11 Les données naturelles constituent un premier élément d'explication de la répartition des activités et par conséquent de la structuration du territoire. La contrainte du milieu naturel est le signe d'une très relative adaptation de l'homme à celui-ci. Le pays se divise en deux secteurs bien distincts (carte 1), de part et d'autre du río Paraguay.

Carte 1 : Le Paraguay dans le cone sud [afficher]

Sur la rive droite, c'est le Chaco, région occidentale, plaine semi-aride très peu occupée. Bien qu'elle compte pour plus de $60 \%$ de la superficie du territoire national, soit $220000 \mathrm{~km}^{21}$, elle ne concentre guère plus de $2 \%$ de la population. L'activité agricole y est résiduelle et marginale, le Chaco demeure une région d'élevage. Il s'agit plus précisément d'un d'élevage extensif impliquant la formation d'une structure latifundiaire. Les cultures y sont par conséquent rares et principalement fourragères (graminées pérennes). De fait, seules les communautés mennonites paraguayennes, immigrées au cœur du Chaco à partir des années vingt et trente, ont implanté un système agricole diversifié et moderne dans cet espace enclavé aux conditions naturelles difficiles. Le fait mérite d'être mentionné car cette agriculture moderne est bien intégré à la structure productive et territoriale paraguayenne même si en termes d'espace occupé et de population active les résultats apparaissent peu significatifs, preuve que l'implantation humaine en milieu contraignant dépend avant tout de l'état des techniques d'encadrement des communautés qui en font l'expérience.

C'est dans la moitié orientale du pays que la population s'est installée et a construit le Paraguay « utile » puisqu'on y retrouve, sur $160000 \mathrm{~km}^{2}$, une population d'environ 5000000 d'habitants. Une fois encore, il est impossible de saisir les dynamiques du peuplement sans faire appel aux données du milieu naturel. Dans le secteur oriental, c'est dans les plaines alluviales des interfluves du bassin versant du río Paraguay que les populations s'organisent; Asunción, fondée au XVI ${ }^{e}$ siècle sur la rive gauche du cours moyen du río Paraguay, capte l'essentiel des populations au sein de ce dispositif. Traditionnellement et aujourd'hui encore, la population paraguayenne se concentre en majorité dans le secteur central (carte 2). 
Carte 2 : Front pionnier Brésilien et dispositif territorial au Paraguay oriental

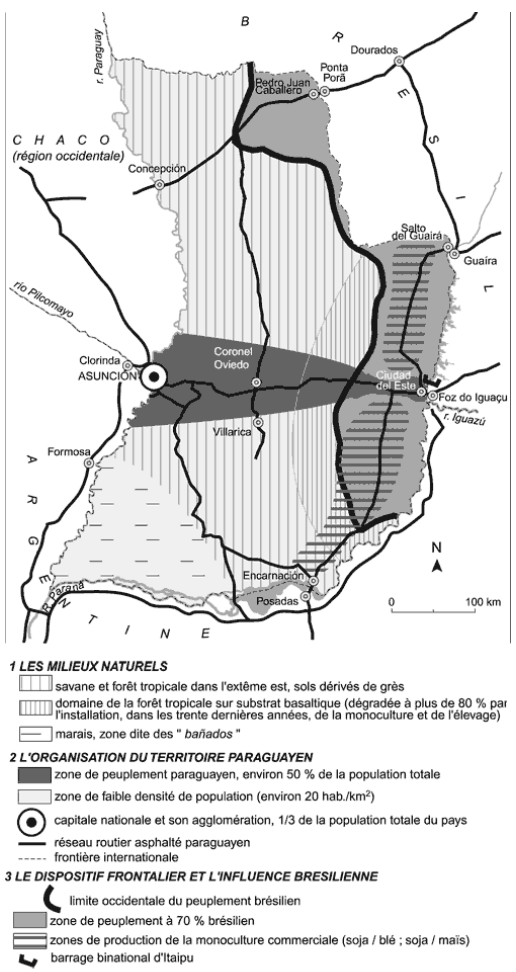

\section{SCHEMA DE L'OCCUPATION DE L'ESPACE PARAGUAYEN}

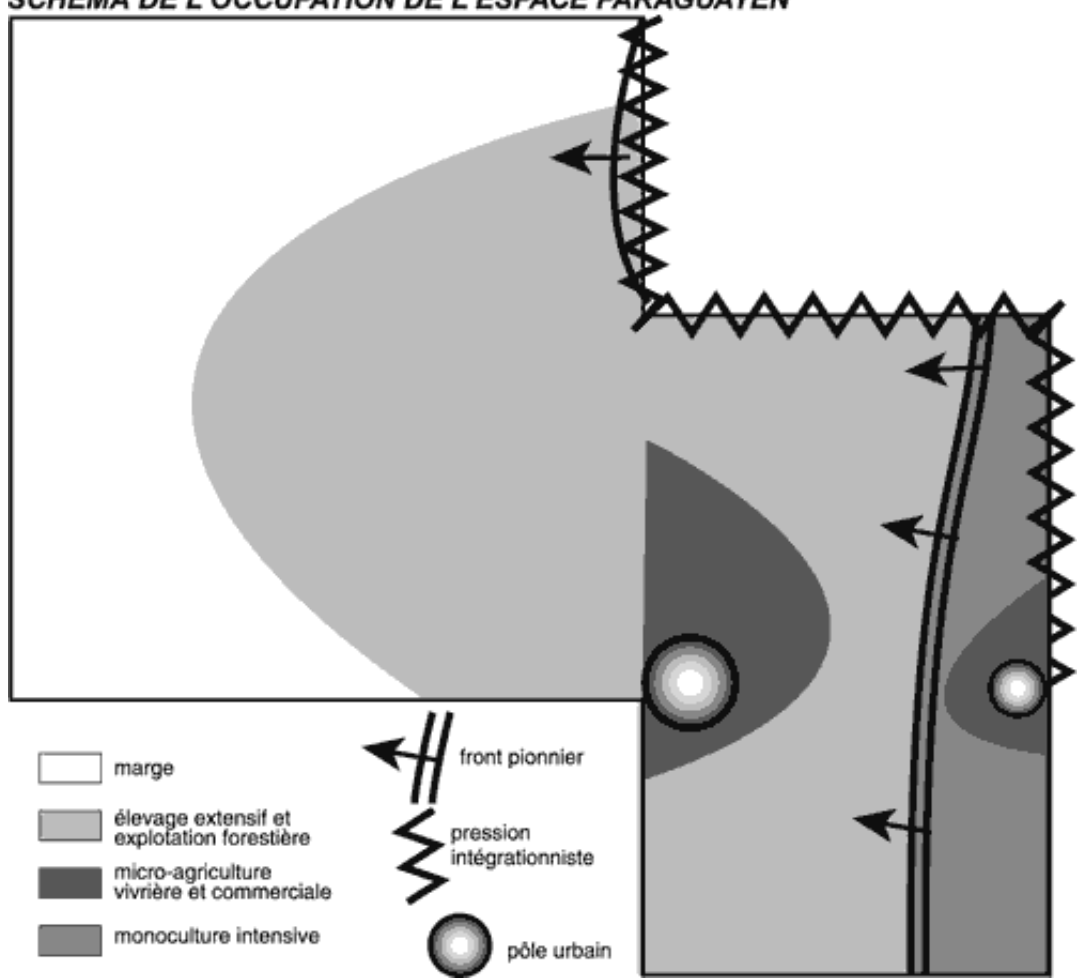

Représenté sur la carte 2, le schéma spatial ancien et fortement polarisé évolue progressivement sous l'effet de l'immigration brésilienne. L'influence brésilienne va contribuer de façon notable à désenclaver les périphéries orientales frontalières du Brésil, espaces qui correspondent en majeure partie au domaine de la forêt tropicale 
semi-caducifoliée dont les substrats basaltiques fournissent des sols riches et profonds que les colons brésiliens vont mettre à profit.

Les fondements historiques de l'inoccupation et de l'apparente inertie des secteurs forestiers orientaux sont multiples. Tout au long de l'époque coloniale et jusqu'à la deuxième moitié $d u$ xIX ${ }^{e}$ siècle, ils constituent à la fois un espace trop vaste à occuper pour une population très faible et isolée, et un rempart naturel aux incursions brésiliennes. À partir de la fin du XIX siècle, on constate la privatisation de l'espace forestier au bénéfice d'investisseurs étrangers. Ils réalisent l'installation progressive d'une structure foncière dominée par la grande propriété. Ces compagnies étrangères contribuent, entre spéculation et extractivisme forestier extensif, au verrouillage de cet espace au riche potentiel agricole.

En conséquence de ce mode d'occupation territoriale, dans les années 1960, et alors que l'installation brésilienne débute, les populations rurales paraguayennes se concentrent dans la large périphérie orientale d'Asunción, dans les départements de Central, de Caacupé, au sud du San Pedro, au nord du Paraguarí, et à l'ouest du Caaguazú (cartes 1 et 2). Ce dispositif spatial est encore aujourd'hui perceptible, non pas tant par l'observation de la répartition de la population qu'au regard de la distribution des activités agropastorales.

L'organisation socio-spatiale actuelle du territoire paraguayen repose sur les fondements solides de tendances anciennes. Au cœur du secteur oriental, l'activité se limite encore pour une large part à la micro agriculture vivrière et commerciale. Les principales productions n'ont guère évolué depuis le xIX siècle. On retrouve le coton, base de la production commerciale, à côté d'une production essentiellement vivrière dont le manioc est le composant principal. L'extrême concentration des exploitations notées dès le $\mathrm{XIX}^{\mathrm{e}}$ siècle se retrouve tout au long du $\mathrm{Xx}^{\mathrm{e}}$ siècle, non compensée par une colonisation vers l'est, trop peu active pour pouvoir faire face à l'explosion démographique qui secoue le Paraguay à partir des années 1950. Les exploitations, en moyenne d'un à deux hectares sur des sols lessivés, n'entretiennent pas la population paraguayenne qui reste bien souvent au-dessous du seuil de pauvreté.

Une surprenante carence foncière, une répartition déséquilibrée de la propriété des terres, un archaïsme des modes de production agricole et une hyper spécialisation de la production, caractérisent le modèle agraire paraguayen lors de la poussée pionnière brésilienne. Compte tenu des potentialités du territoire paraguayen : disponibilité en terres fertiles et aménité des milieux naturels, l'intervention dynamique des pionniers brésiliens allait marquer profondément le système agraire paraguayen.

L'introduction de la monoculture intensive du soja par les Brésiliens au Paraguay

19 Les modes de progression des colons brésiliens s'établissent dans la plus stricte logique pionnière brésilienne. L'installation de l'agriculture spéculative dans l'espace frontalier se réalise en quelques décennies (Pébayle, 1994 ; Kohlhepp, 1999 ; Souchaud, 2000). Il résulte de ce schéma de colonisation que l'espace frontalier, encore largement vierge et nettement marginal il y a une trentaine d'années, est aujourd'hui un espace central au Paraguay. Il vient modifier l'organisation d'un système agraire jusqu'alors relativement stable.

20 L'implantation des Brésiliens débute à la fin des années soixante. Le mouvement s'intensifie dans la seconde moitié des années soixante-dix lorsque s'accélèrent les bouleversements dans les campagnes du Sud. Entre 1985 et 1996, on constate le recul de 
la superficie cultivée au Brésil. Philippe Waniez (2002 : 205) observe que ce recul résulte de la combinaison de facteurs : modernisation des campagnes, désengagement de l'État dans le domaine agricole, variations des cours sur les marchés agricoles internationaux et éventuelles pertes de compétitivité face aux concurrences nouvelles qu'impose l'ouverture des frontières du Mercosud. Cette déprise rurale, parce qu'elle correspond à une situation de crise qui ne limite en rien la demande foncière, stimule et ravive périodiquement la pression migratoire internationale au sein d'une nation traditionnellement migrante ${ }^{2}$. La migration vers les sols forestiers vierges et bon marché du Paraguay s'impose aux paysans lusophones comme l'alternative aux migrations vers les terres lointaines et inconnues, en particulier du sud de l'Amazonie brésilienne. Les migrants du Sud illustrent, par leur préférence accordée à l'espace d'accueil paraguayen, les observations de Philippe Waniez (2002: 150) qui montre l'attractivité des régions limitrophes et l'importance des grands axes de communication dans la structuration des migrations internes au Brésil ${ }^{3}$. Ce sont les colons des États de la région Sud (Paraná, Santa Catarina, Rio Grande do Sul) qui vont imprimer le plus fortement le mode de colonisation, suivant le schéma de modernisation des campagnes qui les avait conduits au « refuge » paraguayen. Paysans en majorité d'origine italienne, allemande et slave, mais rompus aux façons culturales traditionnelles des zones forestières tropicales et subtropicales de l'Amérique, ils innovent peu à peu dans le choix et les modes de cultures. Déjà dans le Brésil méridional, au contact des zones tropicales et subtropicales, domaines de la forêt et de la prairie, l'agriculture intensive était venue au secours de l'élevage en perte de vitesse. La culture intensive et mécanisée du riz va donner naissance à la granja. Cette entreprise agricole familiale va gagner tout le Brésil méridional avant de faire irruption au Paraguay. À mesure qu'elle progressait vers le Nord, les granjeiros l'ont spécialisée dans la culture du soja.

21 Le soja, absent du territoire paraguayen au début des années soixante-dix, occupe 552 456 hectares en 1991 (Ministerio de Agricultura y Ganadería, 1994) et selon les estimations, 1175000 hectares en 2000 (Ministerio de Agricultura y Ganadería, 2000). Cette culture arrive au premier rang de la surface cultivée. On trouve ensuite le maïs, avec 385000 hectares (MAG, estimations 2000). Le maïs, culture traditionnelle du Paraguay, a cependant fortement bénéficié de la progression de la culture du soja puisqu'il lui est associé comme culture d'hiver dans de nombreuses granjas (principalement dans le Canindeyú). Il est par conséquent une des pièces maîtresses du modèle brésilien. Les cultures du manioc et du coton occupent respectivement 250000 et 190000 hectares en 2000 (Ministerio de Agricultura y Ganadería, 2000). Le soja est donc stratégique dans la dynamique territoriale paraguayenne. Si les Brésiliens sont les instigateurs de cette révolution des campagnes orientales paraguayennes, restent-ils aujourd'hui à la tête de cette activité ?

Évolution des structures agraires et foncières

Nous ne reviendrons pas ici sur les processus de marginalisation des populations paysannes paraguayennes et brésiliennes (Palau, Heikel, 1987 ; Kleinpenning, Zoomers, 1991 ; Souchaud, 2000), nous nous centrerons plutôt sur l'analyse de la structure agraire qui s'est mise en place à la frontière orientale.

23 L'impact de la société de colons granjeiros réside avant tout dans la nature d'une activité inédite au Paraguay: la monoculture intensive. Forte demandeuse de terres, elle progresse avec rapidité dans un espace forestier jusque-là resté pour l'essentiel inculte, 
contribuant ainsi à l'augmentation rapide de la surface agricole utile au Paraguay et assurant l'apparition de propriétés aux dimensions moyennes.

Croissance de la surface agricole utile paraguayenne

La culture du soja occupe la première place du secteur agricole paraguayen, en volume de production et en surface cultivée. Mais, chose étonnante compte tenu des potentiels agricoles du Paraguay, on avait rarement vu une production se confiner dans un espace aussi restreint du territoire national. Son influence néanmoins peut se lire au-delà de son espace d'implantation.

Les données du dernier recensement agraire de 1991 (MAG, 1994) (tableau 1) montrent que la surface agricole s'est accrue au rythme annuel moyen de 5,1\%, entre 1981 et 1991, sur l'ensemble de la région Est. On remarque aussi que les données maximales enregistrées concernent les départements de Canindeyú et d'Alto Paraná (respectivement, 9,4\% et 8,1\%), lesquels figurent parmi les départements les plus agricoles de la région ${ }^{4}$.

Tableau 1 : Évolution de la surface agricole utile au Paraguay oriental, 1981-1991

\begin{tabular}{|c|c|c|c|c|c|c|c|}
\hline & $\begin{array}{c}\text { surface } \\
\text { cultrvée en } \\
1981\end{array}$ & $\%$ & $\begin{array}{c}\text { surface } \\
\text { cultivée en } \\
1991\end{array}$ & $\%$ & $\begin{array}{c}\text { taux de } \\
\text { croissance } \\
\text { annuel moyen } \\
1981.91\end{array}$ & $\begin{array}{c}\text { nombre de } \\
\text { propriétés } \\
\text { agricoles en } \\
1991\end{array}$ & $\begin{array}{c}\text { surface } \\
\text { moyerne des } \\
\text { propriétés } \\
\text { agricoles en } \\
1991\end{array}$ \\
\hline $\begin{array}{l}\text { REGION } \\
\text { ORIENTALE } \\
\text { dont }\end{array}$ & 1873037 & 100,0 & 3088399 & 100,0 & 5,1 & 272903 & 11,3 \\
\hline Canindeyú & 135811 & 7,3 & 334331 & 10,8 & 9,4 & 11541 & 29,0 \\
\hline Afto Paraná & 204432 & 10,9 & 445682 & 14,4 & 8,1 & 20875 & 21,4 \\
\hline San Pedro & 255937 & 13,7 & 496977 & 16,1 & 6,9 & 35858 & 13,9 \\
\hline Caazapá & 53466 & 2,9 & 101842 & 3,3 & 6,7 & 19824 & 5,1 \\
\hline Amambay & 209749 & 11,2 & 387163 & 12,5 & 6,3 & 3106 & 124,7 \\
\hline Caaguazú & 195504 & 10,4 & 319049 & 10,3 & 5 & 42254 & 7,6 \\
\hline Concepción & 130071 & 6,9 & 210476 & 6,8 & 4,9 & 14831 & 14,2 \\
\hline Misiones & 46975 & 2,5 & 64533 & 2,1 & 3,2 & 7783 & 8,3 \\
\hline Tapúa & 367599 & 19,6 & 437360 & 14,2 & 1,8 & 38759 & 11,3 \\
\hline Guairá & 65674 & 3,5 & 78045 & 2,5 & 1,7 & 18368 & 4,2 \\
\hline Cordillera & 63761 & 3,4 & 67376 & 2,2 & 0,6 & 19018 & 3,5 \\
\hline Paraguarí & 92799 & 5,0 & 96796 & 3,1 & 0,4 & 24697 & 3,9 \\
\hline Central & 24570 & 1,3 & 24217 & 0,8 & $-0,1$ & 8932 & 2,7 \\
\hline Ñeembucú & 26689 & 1,4 & 24552 & 0,8 & $-0,8$ & 7057 & 3,5 \\
\hline
\end{tabular}

Source : d'après censo agropastoral 1997, Ministerio de Agricultura y Ganadería, Asunción, 1994.

En 1991, les trois départements où la culture du soja est la plus présente sont l'Alto Paraná, l'Itapúa et le Canindeyú. Ils totalisent à eux seuls près de $90 \%$ de la surface totale nationale attribuée à cette production (le soja est absent du Chaco).

À l'intérieur des espaces départementaux, le soja contribue, en 1991, à environ 50 \% de la surface agricole utile dans l'Alto Paraná et l'Itapúa et presque $15 \%$ dans le Canindeyú. Il a donc largement participé au développement de la surface agricole utile paraguayenne (tout au moins dans la décennie 1980). Nous ne sommes pas en mesure de le confirmer dans les années 1990, cependant, durant cette période, la progression $\mathrm{du}$ soja s'est davantage faite par concentration foncière et expulsion de la polyculture traditionnelle que par déforestation (Souchaud, 2000).

Or, la culture de cette légumineuse est une spécialité des immigrés brésiliens. Elle se repère très nettement dans la zone de colonisation brésilienne. Et, lors de nos séjours 
sur le terrain, nous n'avons rencontré aucun Paraguayen pratiquant cette culture dans les départements de l'Alto Paraná, du Canindeyú, de l'Amambay, du Caaguazú et du Caazapá. En revanche, dans le département d'Itapúa et les colonies proches de Encarnación, ce sont les Paraguayens qui cultivent le soja. Ces populations, rappelonsle, ont les mêmes origines allemande ou slave qu'une partie des Brésiliens du Paraguay. Ensemble ils avaient abordé les côtes sud-américaines au début de ce siècle, au sud du Brésil. Mais, alors que la majorité est devenue brésilienne, une fraction abandonnait le Brésil pour gagner le sud du Paraguay en remontant le río Paraná. Ils sont aujourd'hui les seuls Paraguayens à pratiquer une agriculture motorisée.

L'apparition de la propriété agricole moyenne au Paraguay

En élargissant l'échelle d'analyse, on constate que le soja a permis la constitution de propriétés moyennes. La dichotomie, hacienda monumentale et micro-agriculture, bien qu'elle ne soit pas encore généralisée à l'ensemble du territoire, est rompue; la propriété moyenne existe désormais au Paraguay.

En 1991, la superficie moyenne des exploitations agricoles sur l'ensemble de la région orientale est de 11,3 ha (tableau 1). On relèvera que les valeurs les plus importantes désignent les départements de colonisation brésilienne. La valeur figurant pour l'Amambay, 124,7 ha, constitue presque une anomalie dans le cadre régional, mais on rappellera que l'Amambay était un territoire méconnu et le lieu d'importantes activités illicites. Il est fort probable que des propriétés restées non-exploitées ont été déclarées agricoles. Quoi qu'il en soit, nous pouvons éliminer ce département de l'analyse puisque le soja n'y est que très peu présent. En revanche, dans les départements de l'Alto Paraná, de l'Itapúa et du Canindeyú où il est presque intégralement produit, l'examen de la propriété agricole nous renseigne sur plusieurs aspects.

On distinguera d'abord le département de l'Itapúa, territoire de colonisation ancienne. L'irruption du soja s'est faite sur une structure agraire préexistante, avec une moindre disponibilité de terres. Ceci expliquerait que la taille moyenne de la propriété équivaut à la moyenne nationale. En revanche, dans l'Alto Paraná et le Canindeyú, les valeurs respectives de l'étendue moyenne de la propriété agricole sont nettement plus élevées : de 21,4 ha et 29,0 ha. Elles reconfigurent le panorama national car dans les départements de la sous-région Centrale les valeurs sont comprises entre 3 ha et 8 ha; ici, c'est donc la micro-propriété agricole qui domine alors que là c'est la propriété moyenne. Les deux régions concentrent la propriété agricole paraguayenne selon deux pôles aux caractéristiques distinctes.

Le contrepoids exercé par la région frontalière, marquée par l'émergence de la propriété moyenne, est une donnée nouvelle pour le Paraguay. Ce rééquilibrage est dû à l'introduction du soja. Il s'agit d'une production intensive et motorisée. Elle se pratique, en phase d'implantation, et pour des raisons d'économie d'échelle, sur des propriétés moyennes et grandes (entre 50 et $100 \mathrm{ha}$ ). Lors de la première phase du processus pionnier, la progression de l'agriculture motorisée s'opère avec la présence d'une polyculture sur petite parcelle. La polyculture tirant vers le bas la superficie moyenne de la propriété agricole, tout porte à croire que la production du soja a lieu, en 1991, sur des superficies supérieures à la moyenne indiquée, c'est-à-dire 11,3 ha (tableau 1). Ce fait se vérifie (tableau 2) parce que la surface moyenne des exploitations cultivant la légumineuse est supérieure de 10 ha à la moyenne des exploitations agricoles. 
Tableau 2 : Évolution de la culture du soja au Paraguay oriental, 1981-1997

\begin{tabular}{|c|c|c|c|c|c|c|c|c|c|}
\hline & $\begin{array}{l}\text { surface } \\
\text { cuttivée du } \\
\text { soja en } \\
1991\end{array}$ & $\%$ & $\begin{array}{l}\text { nombre de } \\
\text { propriétés } \\
\text { cultivant du } \\
\text { scia en } 1991\end{array}$ & $\begin{array}{c}\text { surface } \\
\text { moyenne des } \\
\text { propriétés } \\
\text { cuttivant du } \\
\text { soja en } 1991 \text {, } \\
\text { en ha }\end{array}$ & $\begin{array}{c}\text { surface } \\
\text { cultivée clu } \\
\text { soja en } 1996, \\
\text { en ha }\end{array}$ & $\%$ & $\begin{array}{l}\text { surface } \\
\text { cultivée du } \\
\text { soja en } \\
1997 \text {, en ha }\end{array}$ & $\%$ & $\begin{array}{c}\text { taux de } \\
\text { croissance de } \\
\text { la surface } \\
\text { cultivée du soja } \\
1996-97\end{array}$ \\
\hline $\begin{array}{l}\text { REGION } \\
\text { ORUENTALE } \\
\text { dont }\end{array}$ & 552456 & 100,0 & 26217 & 21,1 & 833005 & 100,0 & 939652 & 500,0 & 1,2 \\
\hline Alto Paraná & 228504 & 41,4 & 5967 & 38,3 & 347698 & 41,7 & 372696 & 39,7 & 0,7 \\
\hline Itapúa & 210523 & 38,1 & 15132 & 13,9 & 278194 & 33,4 & 290000 & 30,9 & 0,4 \\
\hline Canindeyú & 49030 & 8,9 & 2367 & 20,7 & 84113 & 10,1 & 125481 & 13,4 & 4,1 \\
\hline Caaguazú & 21799 & 3,9 & 1070 & 20,4 & 48000 & 5,8 & 55425 & 5,9 & 1.4 \\
\hline Amarnbay & 15288 & 2,8 & 256 & 59.7 & 30000 & 3,8 & 38000 & 4,0 & 2.4 \\
\hline San Pedro & 17367 & 3,1 & 563 & 30,8 & 23000 & 2,8 & 32050 & 3,4 & 3,4 \\
\hline Caazapá & 8931 & 1,6 & 1161 & 7,7 & 22000 & 2,6 & 26000 & 2,8 & 1,7 \\
\hline Concepción & 187 & 0,0 & 30 & 6,2 & 0 & 0,0 & 0 & 0,0 & 0,0 \\
\hline Corctilera & 12 & 0,0 & 3 & 4 & 0 & 0,0 & 0 & 0,0 & 0,0 \\
\hline Guairá & 237 & 0,0 & 104 & 2,3 & 0 & 0,0 & 0 & 0,0 & 0,0 \\
\hline Misiones & 159 & 0,0 & 26 & 6,1 & 0 & 0,0 & 0 & 0,0 & 0,0 \\
\hline Paraguarí & 414 & 0,1 & 30 & 13.8 & 0 & 0,0 & 0 & 0,0 & 0.0 \\
\hline Central & 3 & 0,0 & 4 & 0,8 & 0 & 0,0 & 0 & 0,0 & 0,0 \\
\hline Ñeembucú & 2 & 0,0 & 4 & 0,5 & 0 & 0,0 & 0 & 0,0 & 0,0 \\
\hline
\end{tabular}

Source : d'après Censo agropecuario 1991 et Producción agropecuaria 95/96 96/97, Ministerio de Agricultura y Ganadería, Asunción, 1994, 1996, 1997

Le département de Canindeyú constitue une entorse à ce schéma, la raison en est qu'il y subsiste, en 1991, de vastes latifundia d'exploitation forestière. D'ailleurs ce département est, lors du recensement, moins concerné par le soja que l'Alto Paraná ou l'Itapúa ; il connaîtra une phase de progression étonnante de la culture du soja dans les années 1990 seulement.

Si nous disposions de ces mêmes données pour les années récentes, on constaterait un resserrement de la taille de la propriété cultivant le soja. En effet, dans les années 1990, la part de la micro-agriculture tend à diminuer, expulsée par un effet de concentration foncière dans un front qui a dépassé sa phase strictement pionnière de première mise en valeur des terres conquises sur la forêt. Par conséquent le soja s'impose plus nettement, mais il dispose de surfaces vierges limitées. Et comme les terres sont plus chères, on constate une réduction générale de la dimension moyenne de la propriété. La situation de l'Itapúa semble le démontrer, là le processus pionnier a débuté depuis longtemps, même si l'introduction du soja est récente. Dans ce département, en 1991, la taille des exploitations de soja est en moyenne de 13,9 ha, les granjas de 100 ha à 500 ha représentent $10 \%$ du nombre total des exploitations de soja et $19 \%$ de la superficie totale cultivée de la légumineuse. Ces données sont, pour l'Alto Paraná et le Canindeyú, respectivement, de $11 \%$ et $34 \% ; 8,2 \%$ et $31 \%$ (MAG, 1994). À l'autre extrémité de l'échelle, toujours pour la même année et pour le soja, les domaines de 10 à 50 ha constituent, dans l'Itapúa, l'Alto Paraná et le Canindeyú, $58 \%, 60 \%$ et $36 \%$ du total des propriétés et, $29 \%, 19 \%$ et $20 \%$ de la superficie de celles-ci. Par conséquent, il semble qu'à terme, la propriété du soja de taille moyenne (de 10 à 50 ha) tend à accroittre son domaine global dans les espaces où la colonisation est plus ancienne. Tout laisse à penser que cette tendance se manifeste aujourd'hui dans les zones d'accélération de la dynamique pionnière, et en particulier dans le Canindeyú.

Il est donc possible de conclure que l'ancienneté du processus pionnier, associée à l'introduction d'une culture motorisée tend à la formation et au renforcement de la 
propriété moyenne par une augmentation de son domaine, et à terme, à son resserrement vers des limites inférieures (environ $20 \mathrm{ha}$ ). Ce point nous semble important car il viendrait pondérer les écrits qui font écho aux témoignages que nous avons pu recueillir sur place, lesquels insistent uniquement sur le fait que la progression de la granja engendre un processus expulsif dans les campagnes accompagné d'une limitation de l'accès à la propriété agricole. La concentration foncière est avérée et vigoureuse, mais elle se traduit par la substitution des populations rurales, davantage que par une désertion des campagnes.

Examinons maintenant l'expérience, plus ancienne dans ce domaine, de la rive gauche du Paraná, dans l'État brésilien du Paraná. En 1998, on a pu constater que dans la région de Maringá où la culture du soja est déjà ancienne, le parcellaire est plus resserré que dans les paysages paraguayens. Selon un technicien de la coopérative COCAMAR, $70 \%$ des producteurs possèdent entre 10 ha et $20 \mathrm{ha}$. Ce constat suggère quelques réflexions, alors que cette région constitue l'un des «nouveaux moteurs du développement brésilien $^{5} »$ : la première est que l'établissement d'une structure agraire dominée par la propriété moyenne devrait, en principe, et dans un pays écrasé par la fazenda improductive, être le signe de la démocratisation de l'accès au foncier. Pas nécessairement cependant, la propriété moyenne demeure en réalité très sélective économiquement, et la sélection porte sur la structure économique qui l'accompagne. La motorisation et l'amélioration des techniques constituent l'essentiel de l'investissement, lequel est indispensable dès la mise en culture. La logique pionnière traditionnelle est dépassée, désormais les colons doivent pouvoir compter sur un capital substantiel.

Le deuxième élément de réflexion permet d'expliquer la diminution, à terme, de la surface de la propriété moyenne, pour des raisons économiques liées au désenclavement progressif de la zone de colonisation. Les difficultés d'approvisionnement et d'accès aux réseaux commerciaux constituent un surcoût financier qu'une économie d'échelle contourne. Voilà pourquoi, dans un premier temps les propriétés sont globalement plus vastes. C'est cette dépendance directe aux structures spatiales (réseaux de communication, commerciaux et financiers), à grande et petite échelle, qui détermine la réussite de la granja de soja. Dans ce processus, l'État a un rôle considérable à tenir; par l'assistance financière, l'établissement d'une infrastructure et la gestion rationnelle de la politique agricole, il peut escamoter ces surcoûts et donc créer les conditions d'une accession démocratique à la propriété foncière. Et c'est, nous semble-t-il, cette dernière étape qui fait défaut au Paraguay.

Un dernier argument nous ramènera à la question de l'interaction migrationsenvironnement. L'acquisition de propriétés d'envergure (tendant vers une moyenne de 100 hectares) s'inscrirait dans une prise de conscience des contraintes inhérentes aux milieux faiblement anthropisés. Les immigrants brésiliens, décidés à développer la monoculture intensive, connaissent ou estiment les seuils de rentabilité d'une exploitation destinée à la culture du soja en terme de surface. On peut donc penser que les superficies acquises habituellement sont bien au-delà de ces seuils et assurent largement la viabilité de l'entreprise. Or c'est oublier que les terres forestières ne sont pas d'emblée intégralement défrichées (faute de moyens et/ou compte tenu de la nécessité d'assurer au plus vite une récolte), et que par conséquent, sur les propriétés forestières récemment acquises, la surface effectivement mise en culture progresse d'année en année; à mesure que les réserves forestières s'amenuisent la superficie 
globale des exploitations diminue. Les immigrants-pionniers ne sont donc pas intrinsèquement des dévoreurs d'espace et de forêt. Ils le sont par la nature et l'exercice particulier de leur activité et dans la mesure des contraintes socioéconomiques essentiellement extérieures qui leurs sont imposées.

Ajoutons que l'acquisition d'une terre constitue une épargne pour ces pionniers, que son prix est bas quand la pression foncière est encore limitée si bien que c'est la valeur monétaire de l'hectare qui fixe la superficie foncière moyenne; que la pression migratoire s'affermisse et la superficie moyenne est susceptible (en dehors de certaines contraintes politiques) de tendre à la baisse.

La permanence d'une structure foncière inégalitaire

Nous avons vu que l'introduction de la culture du soja a permis un net accroissement de la surface agricole utile et a contribué à l'introduction de la propriété moyenne au Paraguay. La structure foncière du pays reste néanmoins marquée par sa répartition extrêmement inégale (tableau 3).

Tableau 3 : Répartition de la surface agricole cultivée par taille des propirétés au Paraguay 1981-1991

\begin{tabular}{|c|c|c|c|c|c|c|c|c|c|c|}
\hline & $\begin{array}{l}\text { nornbre } \\
\text { en } 1991\end{array}$ & $\begin{array}{l}\% \text { du } \\
\text { totel }\end{array}$ & $\begin{array}{c}\text { surface en } \\
1991\end{array}$ & $\begin{array}{l}\% \text { du } \\
\text { totel }\end{array}$ & $\begin{array}{l}\text { norribre } \\
\text { en } 1981\end{array}$ & $\begin{array}{l}\% \text { clu } \\
\text { total }\end{array}$ & $\begin{array}{c}\text { surface en } \\
1981\end{array}$ & $\begin{array}{l}\% \text { du } \\
\text { total }\end{array}$ & $\begin{array}{l}\text { yariation du } \\
\text { nombre } \\
\text { entre } 1981 \\
\text { et } 1991 \text { en } \\
\%\end{array}$ & $\begin{array}{c}\text { variation de } \\
\text { la surface } \\
\text { entre } 1981 \\
\text { et } 1991 \text { en } \\
\%\end{array}$ \\
\hline$<1$ ha. & 10363 & 3,7 & 3682 & 0,1 & 7701 & 3,4 & 2707 & 0,1 & 34,6 & 36,0 \\
\hline $1<5$ ha. & 88751 & 32,1 & 160083 & 4,0 & 64008 & 28,3 & 111678 & 5,0 & 38,7 & 43,3 \\
\hline $5<10$ ha. & 65420 & 23,7 & 257264 & 6,5 & 48478 & 21,5 & 184636 & 8,2 & 34,9 & 39,3 \\
\hline $10<20$ ha. & 64975 & 23,5 & 393914 & 9.9 & 55362 & 24,5 & 309892 & 13,8 & 17,4 & 27.1 \\
\hline $20<50$ ha. & 30322 & 11,0 & 370506 & 9,3 & 35073 & 15,5 & 329895 & 14,7 & $-13,8$ & 12,3 \\
\hline $50<100$ ha. & 6912 & 2,5 & 207001 & 5,2 & 6623 & 2,9 & 162999 & 7,3 & 4,4 & 27,0 \\
\hline $100<200$ ha. & 3771 & 1,4 & 233623 & 5,9 & 3679 & 1,6 & 220921 & 9,9 & 2,5 & 5,7 \\
\hline $200<500$ ha. & 2888 & 1,0 & 389840 & 9,8 & 2547 & 1,1 & 164441 & 7,3 & 13,4 & 137,1 \\
\hline $500<1000$ ha. & 1156 & 0,4 & 285671 & 7,2 & 816 & 0,4 & 80864 & 3,6 & 41,7 & 253,3 \\
\hline $1000<5000$ ha. & 1429 & 0,5 & 730094 & 18,4 & 1084 & 0.5 & 242653 & 10,8 & 31.8 & 200,9 \\
\hline $5000<10000$ ha & 364 & 0,1 & 441269 & 11.1 & 233 & 0,1 & 123497 & 5,5 & 56,2 & 257,3 \\
\hline$>10000$ & 245 & 0,1 & 504796 & 12,7 & 222 & 0,1 & 308145 & 13,7 & 10,4 & 63,8 \\
\hline TOTAL & 276596 & 100,0 & 3977745 & 100,0 & 225826 & 100,0 & 2242268 & 100,0 & 22,5 & 77,4 \\
\hline
\end{tabular}

Source : d'après, Censo Agropecuario 1991, Ministerio de Agricultura y Ganadería, Asunción, 1994

41 En 1991, on constate que la micro-propriété agricole, jusqu'à 5 hectares, constitue environ $35 \%$ du nombre total des exploitations et ne représente que $4,1 \%$ de la surface totale cultivée au Paraguay. À l'opposé, on observe que les grandes propriétés, plus de 500 hectares, ne représentent que $0,7 \%$ du nombre total des exploitations mais surtout, accumulent $49,4 \%$ de la surface cultivée au Paraguay. Ce constat chiffré a une conséquence sociale directe dans un pays où encore plus de $50 \%$ de la population, réunie en foyers comptant en moyenne de 4,5 à 5 membres, est occupée par le secteur de la polyculture traditionnelle. La grande majorité de la population rurale doit se contenter dans le meilleur des cas d'une propriété permettant à peine à l'autosuffisance familiale.

L'observation de l'évolution de la structure foncière, entre les deux recensements, permet de dégager plusieurs éléments (graphique 1). On constate à l'échelle du pays, le renforcement de la structure inégalitaire. Les plus fortes augmentations, tant en nombre qu'en superficie, se situent dans les classes extrêmes. L'augmentation relative est égale, mais elle correspond à un creusement des écarts en terme d'occupation 
spatiale. Un renforcement de la concentration foncière est étonnant si on considère que l'augmentation moyenne annuelle de la surface agricole, entre 1981 et 1991, fut de $5,1 \%$, alors que le taux d'accroissement naturel moyen annuel de la population a été, pour la période 1982-1992, de 3,2\% (D.G.E.E.C., 1994) (il est en outre pondéré par une forte évolution de l'urbanisation qui soulage la pression dans les campagnes).

Les Brésiliens sont responsables de l'augmentation de la surface agricole utile, durant la période 1981-1991 et au-delà. En revanche, l'introduction de la moyenne propriété brésilienne est plus difficile à évaluer quant à ses conséquences sur l'ensemble de l'espace agraire. Rappelons qu'en 1991, date des études statistiques les plus récentes, il est encore trop tôt pour mesurer précisément l'ensemble des conséquences spatiales de l'irruption brésilienne dans le secteur agricole. En effet, le processus pionnier est inégalement avancé dans l'espace "brésilien» tel que nous l'avons défini, et préalablement à la réduction de la granja vers une superficie moyenne, de 20 à 100 ha, une première acquisition foncière se réalise par l'achat de domaines plus vastes.

Pourtant, certains indices sont déjà perceptibles. L'examen de la répartition de la propriété agricole par taille au Paraguay oriental (cartes 3 et 4) nous indique qu'à l'intérieur des départements frontaliers, à dominante brésilienne, la propriété agricole entre 10 ha et 100 ha est, en valeur absolue comme en valeur relative, mieux représentée que dans les autres départements de la région orientale.

Carte 3 : Répartition de la micro-propriété agricole, par taille et par département, au Paraguay oriental en 1991 [afficher]

Source : d'après Censo Agropecuario 1997, MAG, Asunción, 1994, SOUCHAUD 2000

Carte 4 : Répartition de la petite et moyenne propriété agricole, par taille et par département, au Paraguay oriental en 1991 [afficher]

Source : d'après Censo Agropecuario 1991, MAG, Asunción, 1994, SOUCHAUD 2000

Inversement, la micro-propriété agricole y est sous-représentée par rapport au panorama national. À l'échelle de l'ensemble du territoire oriental, on note une forte croissance de la petite et de la micro-propriété et en revanche, le recul relatif de la moyenne propriété. Les tendances que nous observons maintenant, grâce à la cartographie de ces données par département, illustrent que dans la région frontalière, le soja a bien contribué à une mutation de la structure agraire. Les Brésiliens cultivateurs de soja ont introduit la parcelle moyenne au Paraguay et bien que les campagnes granjeiras soient expulsives, la micro-propriété, qui résulte d'une extrême concentration foncière, n'atteint des extrêmes que dans la région centrale, espace où les Brésiliens sont absents. Il faudrait évidemment vérifier si la petite propriété se parcellise davantage ou non. En somme, il s'agirait de savoir si la région frontalière suit la tendance générale en cours au Paraguay, c'est-à-dire une marginalisation, voire une exclusion accrue des populations les plus démunies du secteur agricole. Il nous faudrait, pour préciser cet aspect, pouvoir bénéficier des données représentées sur les cartes 3 et 4 , au niveau des districts, ce que le recensement n'a jamais réalisé. Néanmoins, nous l'avons constaté lors de nos enquêtes, la stratégie brésilienne n'est pas d'accompagner le morcellement de la petite propriété jusqu'à la formation de la micro-propriété. Les Brésiliens préfèrent bien souvent abandonner les terres plutôt que de se contenter d'espaces arables insuffisants. 
Concernant l'examen général de la structure foncière au Paraguay, la vision synoptique des cartes 3 et 4 trace les principales frontières du Paraguay et nous rappelle, une fois encore, que le secteur agricole est dans ce pays l'élément structurant des grandes dynamiques de la société. On retrouve les territoires représentés auparavant et associés à de fortes géodynamiques : concentration foncière et pression démographique dans la très large périphérie d'Asunción et du département Central, désert humain dans le sudest de la région orientale, dynamisme et originalité de l'espace frontalier oriental, et zone de contact orientée nord-ouest / sud-est, du San Pedro au sud de l'Alto Paraná.

Au terme de l'examen de l'évolution de la structure agraire au Paraguay, il apparaît que

l'introduction de la monoculture du soja a favorisé l'augmentation de la superficie cultivée du territoire paraguay et fait naître un nouveau type de propriété basé sur des parcelles d'une surface moyenne. Cependant, cette évolution reste marginale. La monoculture du soja demeure installée sur des territoires périphériques, nettement circonscrits à la zone frontalière orientale. On retrouve de façon marquée la nette polarisation sociale et spatiale du système agraire paraguayen dont l'élément le plus significatif demeure l'extrême concentration foncière du centre du pays. Les apports des immigrants brésiliens ne sont pas encore notables en dehors du secteur d'installation qui leur est propre. Reste cependant que l'introduction de la monoculture n'est pas fondamentalement responsable de l'accroissement des inégalités foncières au Paraguay.

On ne peut concevoir les nouveautés introduites par les granjeiros en se limitant à l'examen des données quantitatives et générales de la structure agraire, les innovations sont également nombreuses dans les façons culturales et elles permettent d'entrevoir l'évolution des représentations du monde rural.

Innovations agricoles et retouches environnementales

Dans l'optique de la rentabilité de son exploitation agricole, le granjeiro se trouve dans l'obligation d'adopter un certain nombre d'innovations. Ses choix sont déterminés par sa propre évaluation des contraintes économiques et d'une gestion rationnelle du milieu naturel. 


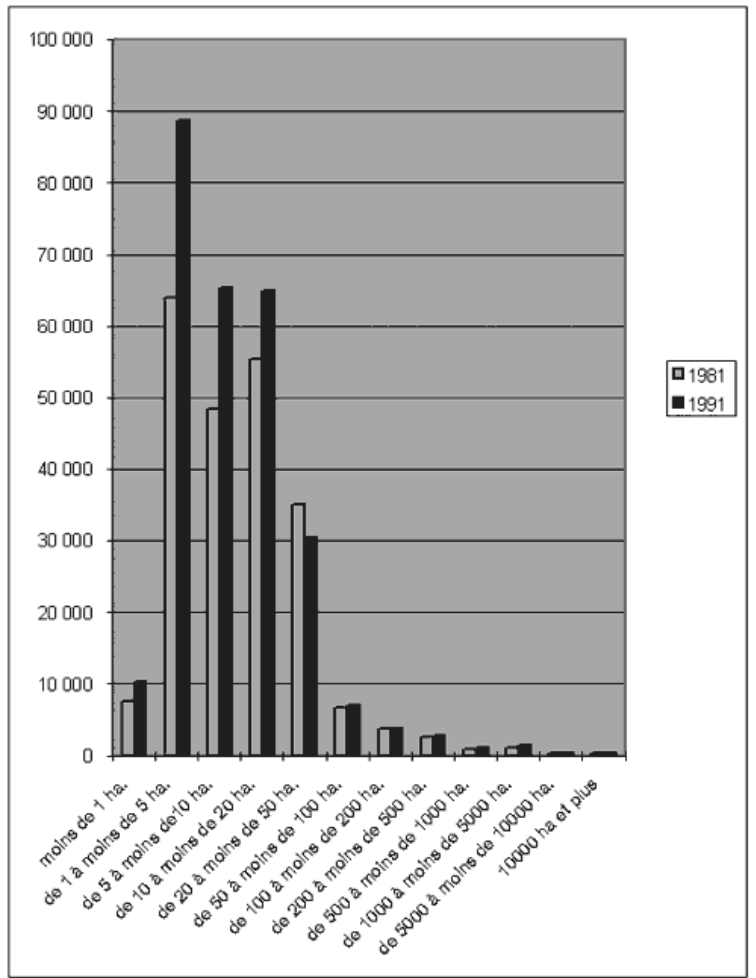

50 Les techniques et les innovations apportées par la granja s'évaluent de différentes façons. À l'intérieur de l'espace paraguayen, la gestion du milieu reste très inégale ; ce qui pourrait d'un côté être considéré comme un pas engagé vers la formation d'un ager pourrait, de l'autre, s'interpréter comme le signe d'un mode agricole purement déprédateur. Le colon se heurte à une tâche délicate : concilier logique pionnière et gestion rationalisée du milieu naturel. Celle-ci est d'ordre écologique et concerne, à des échelles spatiales emboîtées, le moyen, voire le long terme, celle-là relève d'impératifs économiques à courts termes.

51 Les principaux aménagements sont liés à la lutte contre l'érosion des sols. Les atteintes les plus importantes sont portées par les précipitations lesquelles, par leur violence, par leur volume général et ponctuel, attaquent les sols en surface comme en profondeur. Nous ne pouvons ici entrer dans le détail (Neuvy, 1991), nous établirons cependant quelques principes généraux qui établiront le cadre dans lequel s'opèrent les pratiques culturales des colons.

L'érosion, préoccupation majeure des agriculteurs

52 Le milieu tropical connaît de violentes et abondantes précipitations assez bien réparties sur l'ensemble de l'année. Dans la région orientale, les sols argileux ou mixtes, qui prédominent sur des terrains à la topographie peu accentuée, possèdent des régimes hydriques différents qui leur confèrent une résistance inégale face à la rudesse des attaques tropicales. Le terrain argileux, imperméable, va favoriser le ruissellement et donc l'érosion de surface. Dans des sols mixtes en revanche, l'infiltration plus rapide de l'eau entraîne la dissolution et la pénétration de particules nutritives. L'appauvrissement des sols, à terme, a des conséquences importantes sur l'évolution du couvert végétal. Dans tous les cas, chaleur et humidité s'associent à l'altération des minéraux primaires présents dans les sols et provoquent la libération, entre autres, de 
fer : ferrallitisation qui donne sa couleur rouge aux sols mais qui surtout, exprime un déficit minéral.

Vient s'ajouter l'intervention humaine qui accentue, ou au contraire réduit cette vulnérabilité. En cultivant les sols, l'homme les découvre et les déstructure, faisant le choix de telle ou telle culture, il favorise ou non une protection naturelle, en profondeur par le réseau radiculaire, en surface par évaporation ou protection directe. Traditionnellement, des aménagements prennent en compte ces données. En Amérique, l'association, sur une même parcelle, d'une culture haute et d'une culture basse, était pratiquée chez les Mayas (Chonchol, 1995 ; Fumey, 1997), mais elle se retrouve aujourd'hui dans l'agriculture traditionnelle paraguayenne qui associe le manioc à la patate douce, laquelle, rampante et dotée aux larges feuilles, protège les sols de l'attaque des précipitations. Les disponibilités de terres vierges permettaient à l'agriculture traditionnelle d'abandonner les sols après quelques années de mise en culture, la forêt regagnait peu à peu son territoire et régénérait les sols jusqu'au retour des brûlis. Cette rotation n'est désormais plus permise dans les régions de monoculture. Les difficultés auxquelles les agriculteurs doivent trouver une réponse sont importantes comme nous venons de le voir. Les impératifs économiques auxquels ils sont soumis les privent d'une réelle liberté de choix dans les cultures, tout en leur imposant une productivité maximale. Dans ces conditions, une terre fertile mais fragile peut, en une dizaine d'années à peine, perdre sa fertilité relative et engager la viabilité de l'entreprise agricole.

55 En ce qui concerne les façons culturales des granjeiros, le premier point touche la préparation de la parcelle, le second se rapporte aux techniques culturales ellesmêmes. Pour développer ces aspects nous ferons référence à nos travaux de terrain ainsi qu'aux études annuelles conduites par le Ministère de l'Agriculture et de l'Élevage en 1996 (MAG, 1996) et 1997 (MAG, 1997). Les résultats sont basés sur des enquêtes menées dans 150 granjas en 1996 et 154 granjas en 1997. Leur répartition est la suivante : pour 1996, 7 dans le Caaguazú, 66 dans l'Alto Paraná, 16 dans le Canindeyú et 61 dans l'Itapúa ; pour 1997, 16 dans le Caaguazú, 67 dans l'Alto Paraná, 16 dans le Canindeyú et 55 dans l'Itapúa ${ }^{6}$. Les enquêtes visaient principalement l'étude des rendements. Nos propres entretiens, effectués en 1997 et 1998, apporteront des précisions concernant les encadrements, les équipements et la gestion des parcelles sur le long terme.

Défricher

56 La culture du soja n'est pas une culture manuelle. Lors de nos visites, seuls deux des agriculteurs interrogés cultivaient le soja manuellement. Il s'agissait de Brésiliens polyculteurs, et la légumineuse, cultivée sur hectare, n'apportait qu'un complément monétaire.

57 La motorisation permet et impose certains aménagements des parcelles. Ainsi, les champs sont défrichés, les arbres coupés ou renversés par le bulldozer, puis les troncs récalcitrants sont arrachés à l'aide de tracteurs traînant de solides chaînes qui, s'accrochant aux souches, les déracinent. L'ensemble est progressivement mis à feu sur place après séchage, les débris rassemblés en monticules, s'alignent en bandes parallèles, intercalées aux sillons de cultures. D'année en année le feu à raison de ces détritus et laisse des champs parfaitement dénudés. Les plus petits propriétaires, privés d'engins, les louent, mais davantage pour les travaux agricoles que pour la préparation de la parcelle. Ainsi, la superficie de soja mise en culture par rapport à la superficie 
totale de la parcelle dépend, non pas de disponibilités de main-d'œuvre, puisque celleci se résume à la cellule familiale, mais des ressources financières.

En conséquence, certaines parcelles disposeront de secteurs forestiers, alors que d'autres en seront totalement dépourvus ${ }^{7}$. C'est donc naturellement chez les plus petits propriétaires que nous avons constaté la présence d'une zone de forêt ou de jachères arborée (capuera en espagnol, capoeira en portugais ${ }^{8}$ ). Il ne s'agit cependant pas d'un souci écologique conduisant à une rotation rationalisée des cultures mais au fait que la parcelle a été trop récemment acquise pour qu'elle soit totalement préparée, ou que le propriétaire n'est pas en mesure d'assurer seul son entretien.

Une fois la parcelle essouchée, des aménagements complémentaires sont possibles, lesquels sont directement liés à un souci de préservation des sols en vue d'une maximisation des rendements à moyen terme. Il s'agit principalement de la culture en bandes alternantes épousant les courbes de niveau des propriétés installées sur des reliefs. La culture en bandes alternantes n'est pas une action recensée dans l'étude du Ministère.

La culture en bandes alternantes

60 Cette préparation implique l'intervention d'engins pour effectuer de lourds travaux de nivellement. Elle concerne alors les propriétés les plus vastes ou économiquement solides. Les courbes de niveau sont relativement rares dans les paysages paraguayens, étant donné la douceur du relief. De ce point de vue, les versants des plateaux du Paraná (de l'autre côté de la frontière au Brésil) offrent une vision plus complète et plus aboutie du phénomène. Néanmoins, lors de nos passages dans des propriétés susceptibles d'avoir recours à cette pratique (nous ne sommes pas en mesure d'évaluer le seuil d'inclinaison qui rend rationnel cet aménagement), les producteurs de soja affirmaient en grande majorité aménager les cultures en courbes de niveau. Mais il faut ici s'entendre sur les termes, puisqu'en réalité, cet usage a divers degrés de perfectionnement. Ainsi, la bande peut-elle être nivelée, formant un paysage de terrasses, c'est la micro bacia, rarissime au Paraguay. Ou bien encore, les bandes sont simplement séparées par des bourrelets de terre (le murundu) qui freinent l'écoulement hydrique par rupture de l'accélération gravitationnelle. Enfin, elle peut se constituer en une alternance déséquilibrée des cultures (une bande d'une quarantaine de mètres de large de soja pour une bande de quelques mètres de large de maïs) qui vise le même but que l'option précédente, mais ajoute une production.

61 Quand la pratique de la culture en courbes de niveau n'est pas retenue, les reliefs les plus accentués peuvent être totalement occupés par une plante comme le maïs, et ce sans aucun aménagement. On retrouve là, soit une préoccupation pionnière, celle de diversifier la production pour assurer l'autosubsistance en cas de coup dur, soit, dans le cas d'une granja qui pratique également l'élevage intensif, une volonté de s'assurer un complément nutritif hivernal pour le bétail car le maïs constitue dans cette hypothèse une plante fourragère.

62 Une fois les parcelles préparées, il faut planter, cultiver et récolter. Les stratégies et les techniques s'évaluent aux différentes échelles de temps que comprend le calendrier agricole ; l'alternance des cultures se réfère à une gestion annuelle, alors que le choix de tel ou tel engrais chimique ou la décision de récolter se rapporte à une gestion ponctuelle.

Le semis direct ou plantio direto 

direto (portugais) ou siembra directa (espagnol), c'est-à-dire le «semis direct». Il est pratiqué chez presque tous les granjeiros et les enquêtes du Ministère affirment qu'en 1996, il fut réalisé par $65 \%$ de ceux-ci contre $67 \%$ en 1995. La granja pratique la monoculture intensive avec deux récoltes annuelles. En été, les champs sont uniformément recouverts de plants de soja, alors qu'en hiver (d'avril à septembre, comprenant la saison sèche), et par ordre d'importance, on pratique la culture du blé, du maïs ou de l'avoine (système de la culture dérobée). Le rythme intense qu'on impose aux sols doit évidemment en réduire les capacités. Ainsi, un double labour entraînerait un risque de lessivage accru (un sol dénudé et retourné est directement exposé à l'action des pluies). En conséquence, on diminue le temps d'exposition en pratiquant le "semis direct », c'est-à-dire qu'après la récolte du soja qui, selon les années, court de mars à mai, on replante aussitôt et sans labour la culture hivernale. Cette optimisation de la fertilité des sols et la diminution des risques d'exposition sont bénéfiques à court terme ; mais qu'en est-il sur le long ou le moyen terme?

Tout d'abord, notons que le labour est nécessaire de temps à autre. Il permet de renouveler en matière nutritive les couches superficielles lessivées des sols. Il active aussi l'échange gazeux avec les solums, et en particulier permet l'apport d'oxygène, essentiel dans le processus de décomposition des micro-organismes qui fertilisent les sols et dans les échanges chimiques avec les racines. Enfin, il favorise la circulation hydrique. Donc, un labour occasionnel est nécessaire à l'entretien des sols, mais les colons le réalisent à des rythmes différents et souvent insuffisants.

Ensuite l'économie du labour n'assure pas l'économie du nettoyage des champs. Les chaumes de la récolte antérieure doivent disparaître, il faut alors employer des herbicides coûteux. De plus, la dégradation des résidus végétaux par herbicide ne nourrit pas tant que l'enterrement par labour, alors le semis direct devra compenser ce manque par une surcharge d'engrais. On le voit, l'impact écologique du semis direct est important et il est certainement sensible économiquement à court terme.

La rotation des cultures

Les études conduites au Ministère (MAG, 1996 et 1997) nous indiquent que 100 \% des interrogés ont pratiqué dans la même année la culture du blé après celle du soja. Mais d'après nos propres repérages, il apparaît que tous les producteurs ne pratiquent pas deux récoltes annuelles (ils suppriment la récolte hivernale), et parmi ceux qui la pratiquent, tous ne récoltent pas du blé : ils peuvent opter pour le maïs ou l'avoine. Le choix entre ces différents produits nous renseigne sur le mode de gestion de la propriété. L'option de la culture du maïs ou du blé est une réponse à court terme à des impératifs économiques pressants. Les producteurs sont amenés à gérer une propriété en fonction des variations des marchés à terme des produits 9 . Ils sont, aux époques décisives (récolte, approche d'une saison), renseignés quotidiennement sur l'évolution des cours mondiaux et sur les tendances à venir du marché : les suppléments des quotidiens régionaux brésiliens ${ }^{10}$ fournissent régulièrement ce type d'information.

$\mathrm{Au}$ Paraguay cette information est pratiquement absente des médias, cependant les colons savent se tenir au courant par le bouche-à-oreille. Ce phénomène de sujétion à des marchés versatiles exige des producteurs une grande adaptabilité. Ainsi on a vu rapidement disparaitre le tournesol des paysages paraguayens alors qu'il était un produit phare, il y a une dizaine d'années encore. Mais des producteurs, sensibles aux risques financiers qui pèsent sur les productions en développement excessif, adoptent 
de nouvelles productions, telle la canola ${ }^{11}$ qui est utilisée pour produire de l'huile. Toutefois ils restent minoritaires.

Certains producteurs choisissent de ne s'exposer au marché mondial qu'une saison par an (avec le soja) et développent, en hiver, une production à usage local et sans profit financier direct. C'est le cas de l'avoine qui peut avoir deux fonctions, celle de culture verte ou celle de complément hivernal à l'alimentation d'un élevage bovin. Ainsi, l'avoine possède, durant sa période végétative, la faculté de régénérer les sols, en même temps qu'elle les protège des intempéries. Arrivée à maturité, elle est utilisée comme engrais vert, on laisse alors les plants se décomposer sur pied. Enfin, c'est un ensilage vert, tout comme le lolium perenne (azevém en portugais) qui est une graminée. Ces plantes sont utilisées pendant les gelées hivernales de juillet pour nourrir le cheptel bovin. On compte également le maïs parmi les ensilages.

La diversification de la production et en particulier l'apparition de cultures vertes, nous les avons remarquées principalement dans le sud de l'Alto Paraná. Il semble qu'elles soient moins d'usage dans le Canindeyú du fait que le processus pionnier y est retardé, et que, par conséquent, les terres sont plus fertiles remettant à plus tard l'effort d'adaptation. À nouveau, un regard porté sur l'autre rive du fleuve Paraná nous renseignerait sur les potentiels de cette société granjeira. Là, les rotations, plus abouties, sont triennales et intègrent une culture verte (Kohlhepp, 1991).

Pour l'heure, tout porte à croire que les transferts d'innovations se feront entre l'Alto Paraná et le Canindeyú, car la mobilité pionnière à l'intérieur de la zone est importante. Ainsi, des témoignages recueillis dans le sud de l'Alto Paraná nous indiquent que de nombreux pionniers locaux migrent vers les secteurs boisés du sud-est du Canindeyú.

On constate que les Brésiliens, toujours soucieux d'optimiser la production, ont introduit l'utilisation généralisée d'intrants. En effet, les semences sont sélectionnées, hybrides de diverses origines, et les sols corrigés et traités. Afin d'examiner ces éléments, nous allons suivre le travail semestriel de la culture du soja dans la région de La Paloma, Canindeyú.

Un exemple de gestion d'une " granja » au Paraguay

Notre propos s'appuie sur le témoignage d'un Brésilien, propriétaire d'une granja et d'un magasin d'intrants et de pièces agricoles. Il introduit à la présentation de l'économie de l'exploitation granjeira. Les éléments proposés ensuite se rapportent à toute exploitation de soja, laquelle se caractérise par un haut niveau d'exigence puisqu'elle constitue la culture principale de l'exploitation, alors que la culture d'hiver est considérée comme accessoire par le producteur. Il la met en route selon ses disponibilités financières, c'est-à-dire en fonction des bénéfices réalisés et des facilités de crédits offertes par les banques. Par conséquent l'investissement en intrants sera variable et moins soutenu.

73 La préparation des sols commence en octobre et le semis se fait en novembre ou en décembre, voire en janvier pour certaines variétés de soja. La première étape consiste à répandre des herbicides liquides dilués à de l'huile végétale pour dessécher le couvert végétal résiduel (en cas de plantio direto). Il existe quantité de variétés d'herbicides aussi le producteur fera un choix en fonction de ses observations (vigueur d'une certaine herbe par exemple), du prix et de la disponibilité des produits dans la région. À ce stade, le tracteur pulvérise 2,5 litres de produit par alqueire (mesure brésilienne qui correspond ici à 2,42 ha). Ensuite, si le plantio direto n'est pas l'option choisie, un disque 
retourne la terre à 10 ou $15 \mathrm{~cm}$ de profondeur. Dans cette région aux sols mixtes, la composante de grès oblige à ne pas entrer profondément dans les sols. Les semences sont alors réparties en même temps qu'on répand un engrais. Chaque ligne est séparée d'environ $40 \mathrm{~cm}$ et 24 à 28 semences sont déposées par mètre selon le taux de germination qui normalement s'établit à $95 \%^{12}$.

Un second traitement intervient entre vingt et trente jours après le semis. Il s'agit de l'épandage d'herbicides associés, les quantités utilisées varient selon le produit ${ }^{13}$. Un troisième traitement suit, l'épandage d'insecticides; selon la vigueur des fléaux, on peut compter jusqu'à cinq interventions durant toute la germination et la floraison. Les deux principaux vulnérants sont la chenille ( $a$ lagarta) et la punaise (o percevejo, appelée familièrement fide fide $)^{14}$. Vingt jours avant la récolte, rien ne doit être appliqué, car elle pourrait se révéler toxique. Elle est lancée au début du mois de mars et se termine à la fin avril, parfois même un peu au-delà.

Ce rapide examen de l'activité agricole du granjeiro montre que celui-ci vise à une maximisation des rendements par un effort à court terme de préservation de la qualité des sols en vue de leur rentabilité optimale. Mais les granjeiros de la région orientale conservent une logique pionnière prédatrice; les efforts consentis visent tout au plus quelques années antérieures. Enfin on retiendra la lourde contrainte financière qui pèse sur la granja.

76 Ajoutons que la relative "facilité » du milieu (richesse des terres agricoles, climat favorable à deux cultures annuelles, relief peu accentué) limite la variété des aménagements du domaine agricole, tout en lui assurant de confortables rendements. Mais la granja du Paraguay connaît des difficultés car, comme nous l'ont montré les quelques références tirées du Paraná brésilien, un fort différentiel existe de part et d'autre de la frontière internationale, signe que l'espace paraguayen est un espace qui comporte ses propres contraintes. Côté paraguayen, par exemple, le coût des intrants est plus élevé. Trois solutions s'offrent au producteur :

77 1) Limiter les aménagements et l'application d'intrants, au risque de voir ses rendements baisser sensiblement à court terme, et à long terme de façon irrémédiable.

78 2) Consentir à tous les investissements nécessaires et risquer de voir sa marge bénéficiaire se réduire considérablement (il peut également réaliser des économies d'échelle en augmentant sa surface productive).

79 3) Adopter une logique qui consiste à cultiver intensément sa parcelle sans souci de préservation à long terme du milieu naturel, et une fois les sols épuisés (à peine une dizaine d'années), quitter sa propriété pour des terres neuves.

80 Mais toutes ces options mettent en lumière un aspect crucial: le colon granjeiro contrôle peu son espace malgré la maîtrise technique et l'expérience acquise dans l'exercice de son activité agricole. Nous serions alors tentés d'interroger le contexte non-agricole, notamment l'inadaptation des structures économiques et politiques. D'une manière générale, l'inadéquation des macro-structures paraguayennes aux modèles de production agricole nationaux entrave la fluidité des échanges et donc réduit les économies d'échelle. Le déficit doit par conséquent être compensé par un effort accru sur les rendements. Qu'en est-il dans le domaine de la production agricole granjeira?

81 Si nous ne sommes pas en mesure d'établir précisément le bilan comptable de la granja, nous pouvons toutefois évaluer le coût des intrants dans cette économie agricole. Son 
poids considérable montre que le granjeiro est un entrepreneur qui doit gérer, d'une saison à l'autre, un lourd investissement. Si l'on considère les coûts en intrants, par exemple (semences, engrais, pesticides et herbicides) ils s'élèvent à 225 US\$ par hectare, alors que le prix d'achat du sac de soja de $60 \mathrm{~kg}$ est d'environ 10 US\$. Les enquêtes du Ministère établissent un rendement moyen pour 1995, 1996, 1997 de 3019 kilos par hectare, soit approximativement 500 US\$ par hectare ${ }^{15}$. Les seuls intrants représentent donc $45 \%$ approximativement du chiffre d'affaires ${ }^{16}$.

Un élément mérite d'être souligné, il concerne les rendements obtenus dans le Paraná Selon un technicien agronome de la COCAMAR (coopérative agricole) les rendements tournent autour de $2400 \mathrm{~kg} / \mathrm{ha}$, nettement moins qu'au Paraguay, alors que la nature des terrains est équivalente. La baisse est imputable à une perte de fertilité des sols, en dépit du fait que, selon le même spécialiste, l'investissement en intrants, dans la région, est en moyenne de 155 US\$/ha alors qu'il est de 225 US\$ côté paraguayen. Cela pourrait nous amener à conclure qu'au Brésil moins d'intrants sont utilisés, mais il s'agit probablement d'une variation du prix des produits de part et d'autre de la frontière. On constate aussi que ces produits, moins chers au Brésil, sont achetés par de nombreux producteurs installés au Paraguay.

Le Paraguay bénéficie actuellement de sols de qualité supérieure, en revanche il souffre des insuffisances de ses réseaux commerciaux qui ont pour effet d'alourdir les coûts de production.

Les dépenses ne se limitent pas aux intrants. Il faut également payer la terre, amortir et entretenir le matériel ou le louer (tracteur, moissonneuse) et assurer le transport de la production jusqu'au silo ${ }^{17}$. Enfin, il faut également négocier un emprunt dont la plupart des producteurs disposent pour le volet agricole. Il s'agit généralement d'emprunts couvrant une saison agricole, le plus souvent contractés auprès de la coopérative (ils fonctionnent sur le système des marchés à terme), et/ou d'une banque commerciale. Là, les taux semblent étonnement élevés, toujours plus de $2,5 \%$ par mois $^{18}$. Ils s'ajoutent au fait que le producteur, dont la propriété est hypothéquée, s'engage à livrer la récolte à un prix préfixé qui le désavantage. La préoccupation du remboursement du crédit est sur toutes les lèvres : il faut "fechar a conta », c'est-à-dire, boucler l'emprunt.

La granja relève d'une performance technique avec une productivité optimale, indice d'une modernité assimilée et contrôlée, mais elle repose sur des structures économiques et commerciales précaires.

Nouvelles ruralités granjeira. L'économie domestique du granjeiro: des campagnes aux villes

Il est difficile de juger du niveau de vie des granjeiros. Leurs plaintes désignent les silos, les banques, les intermédiaires, l'État et le marché. De plus, la forte mobilité des granjeiros peut s'interpréter comme le signe d'un taux élevé de faillites. Mais il est difficile de conclure car le rapport qu'entretient le colon granjeiro avec l'argent et l'espace a quelque chose du jeu; on a pris l'habitude, par goût et par nécessité de prendre des risques dans la gestion annuelle des affaires et à plus long terme dans la mobilité. Quelle est donc la part des échecs qui reposent sur un pari imprudent, car le producteur, c'est certain, ne joue pas à coups sûrs et les marges sont souvent faibles? C'est d'ailleurs peut-être ce qui attire les colons au Paraguay ; conscients de l'insécurité des affaires, ils savent aussi, pour les plus avisés et les plus audacieux, qu'un «bon coup » est possible, car si certaines contraintes apparaissent d'autres sont levées 
(disponibilité foncière, désengagement de l'État qui d'un côté ne soutient pas la production, mais de l'autre n'impose pas de taxation ou de contrôles écologiques, ...).

Qu'en est-il des unités de production que nous avons visitées? Elles semblaient pour la plupart prospères, bien qu'on doive se méfier du «clinquant». La réussite doit s'afficher chez ces granjeiros qui sont devenus l'élite économique, et parfois politique, des campagnes et des nouveaux foyers urbains. Cette réussite se mesure moins dans l'habitat que dans les équipements et les véhicules particulièrement visibles. Les enfants des entrepreneurs et leurs pères passent à toute heure du jour dans le village, en faisant gronder le moteur des véhicules flambants neufs et toujours rutilants malgré la boue ou la poussière ${ }^{19}$. La réussite c'est la consommation et ici comme ailleurs, le véhicule motorisé en est le meilleur signe. Le granjeiro s'est propulsé dans un espacetemps qui lui fait prendre ses distances avec le mode de vie traditionnelle, le terroir n'a plus d'emprise, les limites du finage se gomment, et le temps s'accélère; on se déplace plus vite et plus loin, le regard s'est tourné vers ce qui n'est plus visible et que l'on convoite.

88 L'habitat reste traditionnel. Il est construit en planches de bois sur des modèles architecturaux simples et il fait l'objet d'aménagements sommaires. Les plus prospères construisent en dur, mais les formes sont classiques (plan rectangulaire, couverture à pente double et en tuile, terrasse). Autour d'une cour, on remarque les dépendances et des hangars pour abriter les véhicules.

89 À l'intérieur de la maison, la cuisine est la pièce centrale où se situe le poste de télévision qui permet aux colons de suivre les chaînes brésiliennes grâce à une antenne parabolique. Cette pièce n'est utilisée que par la famille et si l'on reçoit c'est dehors sur la terrasse. L'engagement économique et l'ascension sociale ont fait du granjeiro un acteur de plus en plus urbain.

Le mode de vie du granjeiro a très nettement perdu son aspect rural traditionnel bien que la tradition reste essentielle chez ces populations, mais elle s'est diluée dans un environnement urbain qui d'une certaine manière à contribuer à la standardisation des attitudes sociales. Ces pionniers ont apporté avec eux un ensemble de pratiques socioculturelles, et pas seulement techniques, en donnant aux formations urbaines récentes une centralité nouvelle.

Conclusion

91 L'intervention des colons brésiliens granjeiros est sans doute une donnée essentielle à l'évolution récente de la société paraguayenne. Ces pionniers spécialisés dans la monoculture intensive $\mathrm{du}$ soja ont rompu l'organisation spatiale traditionnelle $\mathrm{du}$ Paraguay : installés sur les espaces forestiers marginaux, à la frontière du Brésil, ils ont intégré un espace qui est devenu en quelques dizaines d'années la première région agricole du pays. Le soja, absent à la fin des années soixante au Paraguay, est devenu la principale culture du pays, si l'on considère les surfaces occupées et l'impact économique.

Le développement du soja ne s'est pas fait en chassant une activité agricole antérieure. L'expulsion et la marginalisation de la polyculture commerciale et vivrière ont accompagné ce mouvement. Mais elles ont touché essentiellement les paysans intégrés au processus pionnier et donc principalement brésiliens. On doit cependant insister sur le fait que l'espace extrême-oriental représentait, pour l'agriculture traditionnelle 
paraguayenne un glacis d'expansion au potentiel important aujourd'hui difficilement accessible face à une monoculture qui s'impose.

La monoculture du soja permet aussi de remettre en question une structure foncière sérieusement ancrée dans l'opposition latifiundium/minifundium. Le développement d'une agriculture familiale productive sur parcelles moyennes est possible au Paraguay, les granjeiros le démontrent dans le secteur frontalier.

Cependant, l'agriculture granjeira ne pénètre pas en profondeur les campagnes paraguayennes. De ce point de vue, l'espace de la monoculture semble fonctionner pour partie en espace clos, les structures agraires qui lui sont propres n'ont pas gagné le reste du territoire, la monoculture elle-même est confinée à l'espace frontalier et les façons culturales propres au granjeiros ne se sont pas diffusées. L'adoption des innovations et les ajustements des techniques d'encadrement sont affaire de temps, relativité temporelle qui s'accorde difficilement au constat d'une rupture des équilibres écosystémiques, conséquence d'une lourde contrainte économique qui pèse sur les granjeiros.

Les atteintes portées aux milieux naturels sont violentes, pour preuve la disparition probable de près de $80 \%$ du couvert forestier au Paraguay oriental, dont la monoculture intensive du soja est largement responsable. Mais signalons que dans le Brésil méridional, où s'est constituée et où subsiste la granja, les signes d'un renouveau écologique sont perceptibles. Le Rio Grande do Sul est le premier État de la fédération brésilienne à inverser la courbe de déforestation. Depuis 1983, la forêt reconquiert l'espace cultivé, elle a augmenté sa superficie de 3370000 ha totalisant désormais 4955600 ha $^{20}$. Doit-on y voir l'évolution d'un modèle agraire, celui de la granja, vers l'intégration de la donnée écologique, ou simplement le résultat d'un déplacement géographique, notamment au Paraguay, des dommages naturels? Les phases de croissances pionnières sont inévitablement déprédatrices, l'histoire le démontre en quelque endroit que ce soit sur la planète. Le milieu est l'un des régulateurs (à grands frais certes) des tensions économiques et sociales; le migrant-pionnier est avant tout contraint par une logique socio-économique qui le met en présence, par sa capacité de mobilité, de réserves naturelles abondantes. La "prodigalité » est un moment historique de la constitution complexe des territoires, processus au cours duquel alternent déséquilibres, ruptures et rééquilibrages ${ }^{21}$. La question qui se pose maintenant, au regard de la rapidité avec laquelle sont conduits les défrichements dans les pays du Sud, est de savoir si les progrès technico-scientifiques n'imposeront pas une dégradation irrémédiable des milieux naturels, notamment par l'artificialisation extrême des milieux naturels (introduction d'organismes génétiquement modifiés, par exemple).

96 Au-delà des impacts de la société granjeira sur les systèmes agraires et le milieu naturel au Paraguay, il est un domaine de la société paraguayenne où s'engagent d'importantes mutations. Les représentations de l'espace rural que forgent les granjeiros introduisent un continuum rural/urbain. La société granjeira est à l'origine de l'intégration et du développement sans précédent des structures urbaines paraguayennes, signe d'une évolution profonde et sans précédent d'une société jusque-là agraire. 


\section{BIBLIOGRAPHIE}

BANCO CENTRAL DEL PARAGUAY (1998) Estadísticas económicas, Asunción, BCP, n 426, 138 p.

BANCO CENTRAL DEL PARAGUAY (2000) Boletín estadístico, Asunción, www.bcp.py.

BANQUE MONDIALE (2001) World development report 1999/2000, Banque mondiale, www.worldbank.org.

CHONCHOL Jacques (1995) Systèmes agraires en Amérique latine. Des agricultures préhispaniques à la modernisation conservatrice, Paris, Institut des hautes études de l'Amérique latine, coll. Travaux et Mémoires de l'I.H.E.A.L, $\mathrm{n}^{\circ} 62,366$ p.

DOMENACH Hervé, PICOUET Michel (2000) Population et environnement, Paris, PUF, 127 p.

DOMENACH Hervé, PICOUET Michel (1995) Les migrations, Paris, PUF, 127 p

FUMEY Guy (1997) L'agriculture dans la nouvelle économie mondiale, Paris, PUF, 379 p.

HAESBAERT Rogério (1999) Regiões transfronteiriças e migração brasileira em países do Mercosul » in VII Encontro Nacional da ANPUR-Assoc. Nac. Planej. Urbano e Regional, Porto Alegre.

I.H.E.A.L. (1981) Les phénomènes de frontières dans les pays tropicaux, Paris, Travaux et mémoires de l'I.H.E.A.L., Credal, 456 p.

KOHLHEPP Gerd (1999) Incorporação do espaço fronteiriço do leste do Paraguai na esfera de influência brasileira in Barbara Potthast., K. Kohut, Gerd Kohlhepp Éds., El espacio interior de América del Sur: geografía, historia, política, cultura, Frankfurt, Madrid, Centro de Estudios Latinoamericanos de la Universidad Católica de Eichstätt, série A : Actas, 19, Vervuert, Iberoamericana, pp. 205-225.

KOHLHEPP Gerd (1991) Mudanças estruturais na agropecuária e mobilidade da população rural no Norte do Paraná (Brasil), Revista Brasileira de Geografia, Rio de Janeiro, 53 (2), pp. 79-94.

MINISTERIO DE AGRICULTURA Y GANADERIA (2000) Producción agrícola, 1998/1999 y 1999/2000, Asunción, Dirección de Censos y Estadistidísticas Agropecuarias, http://www.una.py/sitios/mag/ dcea.

MINISTERIO DE AGRICULTURA Y GANADERIA (1997) Producción agropecuaria 1996/97, síntesis estadística, informe final, Asunción, Dirección de Censos y Estadistidísticas Agropecuarias, MAG, 129 p. \& annexes.

MINISTERIO DE AGRICULTURA Y GANADERIA (1996) Producción agropecuaria 1995/96, síntesis estadística, informe final, Asunción, Dirección de Censos y Estadistidísticas Agropecuarias, MAG, 136 p. \& annexes.

MINISTERIO DE AGRICULTURA Y GANADERIA (1994) Censo agropecuario 1991, Asunción, Dirección de Censos y Estadistidísticas Agropecuarias, MAG, cd-rom.

NEUVY Guy (1991) L'homme et l'eau dans le domaine tropical, Paris, Masson, 227 p.

PALAU VILADESAU Tomas et HEIKEL M. V. (1987) Los campesinos, el Estado y las empresas en la frontera agrícola, Asunción, BASE (Investigaciones Sociales, Educación, Comunicación), PIPSAL (Programa de Investigaciones sobre Población en América Latina), 333 p.

PALAU VILADESAU Tomas (1996) Migração transfronteiriça entre Brasil e Paraguai : o caso dos brasiguaios in Neide Patarra Lopes (coord.), Emigração e imigração internacionais no Brasil 
contemporâneo, Programa Interinstitucional de Avaliação e Acompanhamento das Migrações Internacionais no Brasil, Campinas, Vol. 1, FNUAP, 2 éme éd., pp. 200-207.

PEBAYLE Raymond (1994) Les Brésilguayens, migrants brésiliens au Paraguay, Revue Européenne des Migrations Internationales, Migrinter, 10 (2), pp. 73-86.

PEBAYLE Raymond (1989) Les Brésiliens, pionniers et bâtisseurs, Paris, Flammarion, coll. Géographes, $361 \mathrm{p}$.

SILVERO RODRIGUEZ R. (1998) La economía paraguaya en 1996/97. Crisis y oportunidades, s.l., Fondación Konrad Adenauer Stiftung, 363 p.

SOUCHAUD Sylvain (2000) La formation d'un espace « brésiguayen » dans l'Est du Paraguay. Migrations pionnières brésiliennes et organisations socio-spatiales dans l'Oriente paraguayen, thèse de doctorat de géographie, dir. M. Guillon et J.-P. Clément, Poitiers, 515 p.

WANIEZ Philippe (2002) Les données et le territoire au Brésil, H.D.R., géographie, Paris X, http:// perso.club-internet.fr/philgeo, $400 \mathrm{p}$.

ZOOMERS E. B. et KLEINPENNING J.M.G. (1990) Colonización interna y desarollo rural : el caso del Paraguay, Revista Geográfica, I.P.G.H, n 112, Méjico, pp. 109-125.

\section{NOTES}

1. -La superficie du Paraguay occidental n'est pas établie avec exactitude.

2. -Le taux de migration interne au Brésil est passé de 9,46 \% à $7 \%$ entre 1991 et 1996, mais le taux de migration vers un autre État est de 36 \% et $37,2 \%$ pour la même période (Waniez, $2002:$ 149).

3. -Le Paraguay est frontalier de la région Sud du Brésil et accessible par la route et le pont internationaux ouverts dans les années soixante.

4. -Il faudrait pondérer ces données avec la surface totale du département pour plus de précision, néanmoins l'indication reste intéressante en raison d'une relative homogénéité de la superficie des départements dans le secteur extrême-oriental. 5. -Selon, El País, 19 mai 1999, ces régions agro-industrielles de l'intérieur du pays (polygone comprenant le Mato Grosso, le Goiás, le sud de la Bahia, le Minas Gerais, l'intérieur de São Paulo et le Paraná) constituent des références en matière de développement tant quantitatif que qualitatif.

6. -La présentation méthodologique du document ne nous donne pas la surface de chaque propriété. L'échantillon a été réalisé d'après le recensement de 1991.

7. -Il existe bien une loi qui oblige à conserver $10 \%$ de sa propriété en couverture forestière, mais elle n'était jusqu'ici pas un impératif.

8. -Du tupi guarani, Kapu'era, c'est « ce qui était de la forêt ». Il s'agit, selon le dictionnaire Aurélio « d'un terrain forestier défriché et/ou brûlé pour la culture ou pour tout autre usage ». Nous avons rencontré ce terme généralement dans le sens d'une jachère ou d'un recru arbustif.

9. -Pour le soja, le blé le maïs et l'avoine, la référence mondiale est le marché du Chicago Board of Trade, le C.B.O.T.

10. -En cela le système de presse brésilien est semblable à celui des États-Unis, la presse régionale se substitue à la presse nationale.

11. -Malgré nos demandes d'éclaircissement, nous ne disposons pas de la traduction de ce terme pris en note lors d'une conversation. 
12. -Le prix du sac de $50 \mathrm{~kg}$ de semences importées est de 35 US\$. Il faut environ quatre sacs et demi par alqueire. Un sac de semences nationales s'échange à 50000 guaranis (18 US\$) ; le produit brésilien coûte 65000 guaranis (24 US\$). Les semences importées sont modifiées par hybridation et sont donc plus productives. Les engrais, à ce stade, se présentent sous forme granulée, et associent phosphore, nitrogène, potasse et calcium. Il faut compter huit sacs par alqueire, à 13 US\$ l'unité.

13. -L'herbicide le plus courant, le "Dinan ", se répand à $80 \mathrm{~g} /$ alqueire, pour un prix de 150 US\$ par $800 \mathrm{~g}$. Il est mélangé avec du « Pivot » à raison d'un litre par alqueire, son prix de vente pour 5 litres est de 225 US\$. De même, il faut mélanger ces produits à de l'huile végétale en comptant 6 litres par alqueire pour une valeur de 60 US\$ les 20 litres. Des herbicides plus conventionnels sont utilisés, il s'agit du « Scepter » (2,5 litres/al à 165 US $\$ / 5$ litres) et du « Trifularina » (3 litres/al à 22 US\$/5 litres), lesquels ne sont associés à aucune huile.

14. - La chenille peut attaquer dès le trentième jour de germination qui débute cinq jours après le semis. La punaise attaque de quarante-cinq à cinquante jours après le début de la germination, pendant la floraison. Le produit couramment utilisé est le " Thiodan » qui coûte 160 US\$ les 20 litres et qui se répand à raison de 2 litres par alqueire. Il est associé ou non à de l'huile végétale.

15. -Il s'agit là de la production réelle, c'est-à-dire corrigée à moins $14 \%$ d'humidité (taux moyen appliqué) et soustraction faite des pertes (récolte, transport, ...).

16. -Environ $77 \%$ des exploitants utilisent des semences améliorées, $98 \%$ des fertilisants chimiques et $100 \%$ des pesticides (MAG, 1997).

17. -C'est là que les intermédiaires deviennent importants.

18. -Valeur minimum quoique déjà extrêmement élevée, même si les taux d'inflation avoisinent au Paraguay les $10 \%: 18,3$ \% en 1994, 10,5 \% en 1995, 8,2 \% en 1996, 6,2 \% en 1997 (Banco central, 1998). Le taux d'escompte avoisine quant à lui les 30 \% (ibidem).

19. -La consommation s'est diversifiée et l'importation s'est développée. Les véhicules dominants sont des tout-terrain importés de Corée du sud, du Japon ou des U.S.A. Les voitures sont souvent des Wolkswagen, marque qui a fait son apparition au Paraguay avec les Brésiliens.

20. -Carlos Alberto de Souza, Folha de São Paulo, 6 juin 2001.

21. -À l'échelle du temps long, les forêts de France, fortement dégradées, sont là pour en témoigner, les réserves forestières se reconstituent alors même que l'agriculture française n'a jamais été aussi productive et performante.

\section{RÉSUMÉS}

Installés au Paraguay, à la frontière du Brésil, sur la rive droite du río Paraná, des immigrants brésiliens ont développé l'agriculture spéculative et engagé la refonte des systèmes de production du monde rural paraguayen. Grâce à l'introduction de l'agriculture intensive d'exportation, ils sont à l'origine d'importantes transformations de la structure agraire paraguayenne, faisant progresser la surface cultivée et inaugurant, dans une structure foncière marquée par l'opposition latifundium/minifundium, l'apparition de la propriété moyenne. 
Malgré les pressions fortes qu'ils exercent sur les écosystèmes forestiers, il se dégage de l'examen des techniques de production que la gestion des écosystèmes envisagée, quoique ponctuellement mise en application, dépend encore largement de contraintes extérieures qui échappent au contrôle des cultivateurs.

Migrations and Transformations of Agrarian Systems : Brazilian Soy Cash Crop in Paraguay. -Settled in Paraguay, close to Brazil border, on the right bank of Paraná river, Brazilian immigrants have developed the speculative farming system and are responsible for Paraguayan rural world production renewing. Due to the introducing of intensive and export cash crops, the Paraguayan agrarian structure is involved into major changes such as the progressing of the cultivated area in the country, the apparition, in a countryside traditionally divide between latifundium and minifundium, of medium rural exploitations. Despite strong pressures onto forestry ecosystems, the study of production techniques shows that ecosystems handling, even if it's considered and sometimes applied, largely depends on external constraints farmers do not control.

Migraciones y mutaciones de los sistemas agrarios : la cultura brasileña de la soja en Paraguay. -Establecidos en el Paraguay, en la frontera de Brasil, en el margen derecho del río Paraná, inmigrantes brasileños desarrollaron la agricultura especulativa y causaron la renovación de los sistemas de producción en el mundo rural paraguayo. Mediante la introducción de la agricultura intensiva de exportación, originaron importantes transformaciones en la estructura agraria paraguaya, realizando la progresión de la superficie cultiva y estableciendo, en un país fuertemente dominado por la oposición latifundio/minifundio, la aparición de la propiedad mediana. A pesar de las presiones fuertes que ejercitan sobre los ecosistemas, resalta del examen de las técnicas de producción que la gestión de los ecosistemas, de relativa eficiencia aun que fuera considerada, depende todavía en gran parte de coacciones exteriores que escapan al control de los agricultores.

\section{INDEX}

Mots-clés : agriculture, environnement, front pionnier, espace rural, propriété, mode de production, Brésiliens

Index géographique : Paraguay

\section{AUTEUR}

\section{SYLVAIN SOUCHAUD}

Maître de conférences en géographie, Université du Maine (France), U.M.R. 6588

Migrinter (Poitiers). sylvain.souchaud@wanadoo.fr 